\title{
A Newborn with Teratogenic Effect of Imatinib Mesylate: A Very Rare Case Report
}

\author{
Namita Jain ${ }^{a}$ Deepak Sharma $^{\mathrm{b}}$ Renu Agrawal ${ }^{\mathrm{c}}$ Adeesh Jain ${ }^{\mathrm{c}}$ \\ a J.C.D. Dental College, Sirsa, ${ }^{b}$ Department of Neonatology, Fernandez Hospital, Hyderabad, and ${ }^{\mathrm{c} D e p a r t m e n t}$ of \\ Pediatrics, S.P. Medical College, Bikaner, India
}

\section{Key Words}

Chronic myeloid leukemia · Imatinib mesylate - Teratogen •

Congenital malformations - Newborn · Pregnancy .

Tyrosine kinase inhibitors

\section{Abstract}

Objective: To report a case of teratogenic effect of imatinib mesylate (IM) in a newborn, whose mother was suffering from chronic myelogenous leukemia and was treated with IM for 4 years, including during her pregnancy. Case Presentation and Intervention: The newborn was diagnosed with microtia of the right ear, preauricular tag on the left side, absence of right depressor angular oris muscle, and imperforate anus. Infantogram showed dextrocardia, hemivertebrae in the thoracic region and cervical spina bifida occulta. The newborn was operated on for the imperforate anus and was discharged in good condition. Conclusion: This case revealed that IM is not safe for the fetus and leads to teratogenicity. Hence, we recommend that pregnant women should not be treated with IM.

(c) 2015 S. Karger AG, Basel

\section{Introduction}

Treatment of chronic myelogenous leukemia (CML) with imatinib mesylate (IM) dates back to June 1998, but in spite of this long experience there is scarce information on the side effects of IM on fertility and/or pregnancy [1]. The manufacturer of IM recommends that women of childbearing age should avoid becoming pregnant while taking the drug, which is based on the results of preclinical trials that have shown teratogenicity in rats, rabbits, and dogs [1].There are very few case reports on the outcome of pregnancy while on IM $[2,3]$. We report a case of a woman treated with IM while pregnant who delivered twins, one of whom had congenital malformations, while the other child and the mother were normal.

\section{Case Report}

A low-birth-weight $(2.25 \mathrm{~kg})$, late preterm (35 weeks) male infant with normal Apgar score was born by a nonconsanguineous marriage to a third gravida (G3P2L2A1) 27-year-old woman. The pregnant woman had regular antenatal checkups, and the baby was born by normal vaginal delivery. Her first pregnancy was ectopic,

Dr. Deepak Sharma, MD, DNB

Department of Neonatology, Fernandez Hospital

Opposite Old MLA Quarters, Hyderguda

Hyderabad, Andhra Pradesh 500029 (India)

E-Maildr.deepak.rohtak@gmail.com 
1

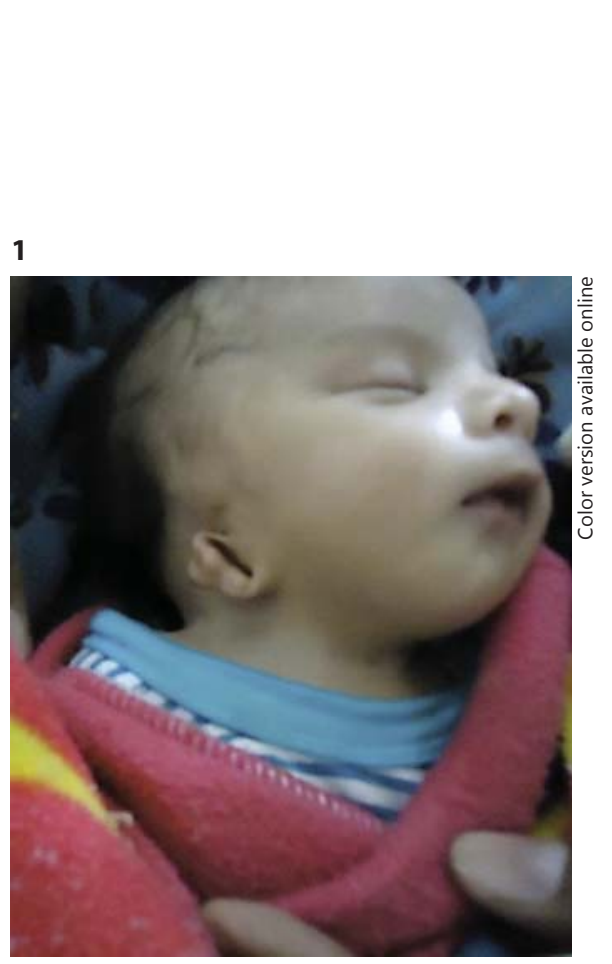

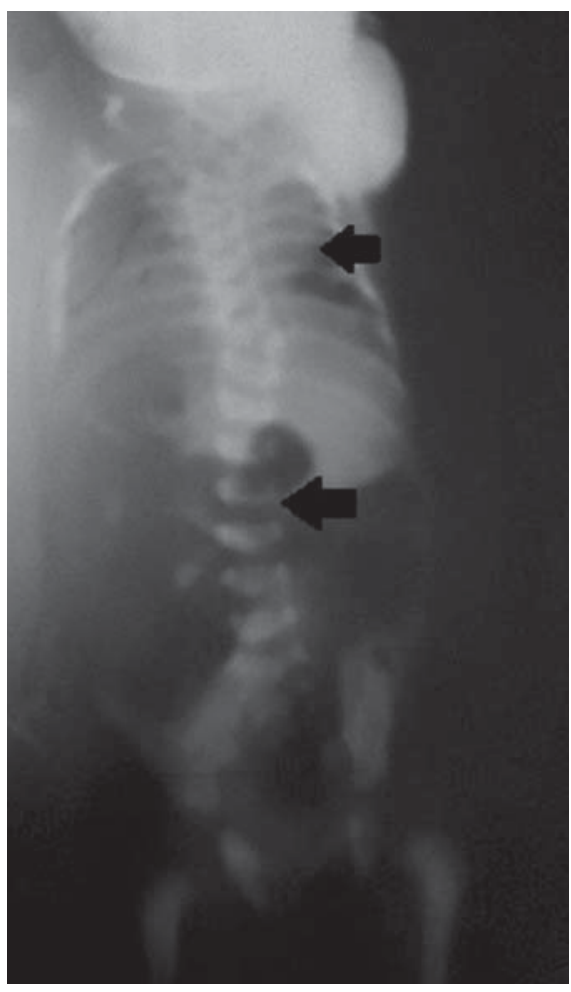

Fig. 1. Child with malformed external ear (microtia).

Fig. 2. Infantogram showing dextrocardia with situs inversus, hemivertebrae, and cervical spina bifida.

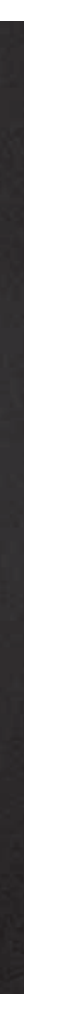

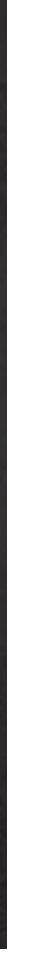

cervical spina bifida.

for which a laparotomy was performed 4 years previously; her second pregnancy resulted in normal vaginal delivery. The baby was healthy and well, without any malformations, and is now about $2 \frac{1}{2}$ years old.

The pregnant mother was on IM during the previous 4 years, including during the first and second index pregnancy. During the index pregnancy the antenatal scans were normal. There was no history of radiation exposure. On examination, the baby was diagnosed with malformed right external ears, preauricular tag on the left side, absence of right depressor angular oris muscle, and imperforate anus (fig. 1). Whole-body X-ray showed dextrocardia, hemivertebrae in the thoracic region and cervical spina bifida occulta (fig. 2). Abdominal and renal ultrasonography showed absent right kidney and ectopic left kidney in the pelvic region. Ultrasound of the head showed mild ventriculomegaly, and ECHO showed situs inversus with no other cardiac diseases. The infant was operated on for the imperforate anus, with an uneventful postoperative period. Hemogram, blood urea, blood sugar, serum calcium, and electrolytes were normal.

There was no family history of any significant illness or any other disorder. The mother was diagnosed with CML during her first pregnancy when her routine hemogram was suggestive of myeloproliferative disorder. Bone marrow examination done at that time showed CML breakpoint cluster region Abelson leukemia virus (quantified using real-time PCR) at a level of $83.04 \%$. She was prescribed IM $400 \mathrm{mg} /$ day that was started about 1 month after diagnosis. She had regular monitoring by hemogram and PCR every 6 months and had complete hematological and cytological remission throughout. The baby was discharged in good condition but was lost to follow-up after 2 months.

\section{Discussion}

The neonate had multiple malformations that included malformed right ear pinna, preauricular skin tag on the left side, absence of right depressor angular oris muscle, dextrocardia, hemivertebrae in the thoracic region, cervical spina bifida occulta, absent right kidney and ectopic left kidney in the pelvic region, mild ventriculomegaly, and situs inversus.

The malformations of this neonate confirmed neonates with teratogenic effects of IM as previously reported [2-4]. The malformations were different for each neonate. Webb and Jafta [2] reported an infant with clinodactyly, short fifth fingers, and slightly downward slanting palpebral fissures, whereas another infant had clinodactyly and low-set ears. Pye et al. [3] reported cases of miscarriage, stillbirth, and renal and vertebral anomalies, as in our case (right renal agenesis and hemivertebrae). Cole et al. [4] reported cases of mothers who had complications that included spontaneous abortion, stillbirth, malformations, and low birth weight. This is the first reported case of its type, with the mother having both a normal infant in one pregnancy and a malformed infant in another pregnancy (although she continued to take the same dose of the drug). This could be due to the difference 
in the susceptibility of the fetus to the same drugs, possibly because of the difference in epigenetics of each child, and it could also be dose related, with longer absorption and concentration in the fetus.

CML is a myeloproliferative disorder of blood stem cells. There is a fusion of the breakpoint cluster region BCR gene on chromosome 9 with the ABL (Abelson leukemia virus) gene on chromosome 22 which results in the formation of Philadelphia chromosome positive $\left(\mathrm{pH}^{+}\right)$ cells. Tyrosine kinase inhibitors, which are used in the treatment of CML, selectively inhibit the activity of the constitutively active protein kinase and regulate the cell cycle. IM is a tyrosine kinase inhibitor which is effective in producing long-term suppression of CML in the majority of patients [1]. Treating physicians do not know much about the treatment of CML during pregnancy most of this information is from case reports using leukapheresis, hydroxyurea, and interferon. The usual side effects of IM include nausea, loose motions, headaches, leg aches/cramps, fluid retention, disturbances in vision, itchy rash, immunity suppression, bruising or bleeding, anorexia, weight gain, neutropenia, thrombocytopenia, anemia, and edema. Other rare side effects include severe congestive cardiac failure and can lead to delayed catchup growth if used in prepubescent children [5]. The dermatological side effects of IM seen include nonspecific skin rashes, pruritus, alopecia, hyperhidrosis, stomatitis, xerostomia, superficial edema, hypopigmentation/depigmentation, hyperpigmentation, mucosal inflammation, lichenoid reaction, psoriasiform rash, and Stevens-John- son syndrome $[6,7]$. The long-term side effects of IM include growth hormone deficiency in patients [8]. It is recommended that women of child-bearing age who are treated with IM should be aware of the potential teratogenicity of IM. Effective contraception should be used during IM therapy to prevent pregnancy [9] because IM crosses the placenta easily and very high concentrations have been found in the placenta [10].

Therefore, we recommend that women should avoid being pregnant while on IM. However, the present case and other reported cases suggest that if a patient inadvertently becomes pregnant while on IM, the pregnancy can also have a favorable outcome. However, in the patient who does become pregnant while on treatment, balancing the risk to the fetus when continuing IM versus the risk to the mother when interrupting treatment remains difficult. We recommend the mother to undergo regular scans or TIFFA (targeted imaging for fetal anomalies) for detecting an associated anomaly in the fetus.

\section{Conclusion}

Pregnant mothers who are on IM may have a normal or a teratogenic outcome, as seen in this case. Hence, they need a strict follow-up.

\section{Disclosure Statement}

The authors have no conflicts of interest to declare.

\section{References}

1 Goldman JM, Melo JV: Chronic myeloid leukemia - advances in biology and new approaches to treatment. N Engl J Med 2003; 349:1451-1464

2 Webb MJ, Jafta D: Imatinib use in pregnancy. Turk J Haematol 2012;29:405-408.

-3 Pye SM, Cortes J, Ault PR, et al: The effects of imatinib on pregnancy outcome. Blood 2008; 111:5505-5508.

-4 Cole S, Kantarjian H, Ault P, et al: Successful completion of pregnancy in a patient with chronic myeloid leukemia without active intervention: a case report and review of the literature. Clin Lymphoma Myeloma 2009;9: 324-327.
5 Druker BJ, Guilhot F, O’Brien SG, et al: Fiveyear follow-up of patients receiving imatinib for chronic myeloid leukemia. N Engl J Med 2006;355:2408-2417.

-6 Brazzelli V, Grasso V, Borroni G: Imatinib, dasatinib and nilotinib: a review of adverse cutaneous reactions with emphasis on our clinical experience. J Eur Acad Dermatol Venereol 2013;27:1471-1480.

7 Grasso V, Vassallo C, Croci G, et al: Tyrosine kinase inhibitors: muco-cutaneous side effects at the microscope. G Ital Dermatol Venereol 2014;149:317-327.
8 Kebapcilar L, Bilgir O, Alacacioglu I, et al: Does imatinib mesylate therapy cause growth hormone deficiency? Med Princ Pract 2009; 18:360-363.

-9 Hensley ML, Ford JM: Imatinib treatment: specific issues related to safety, fertility, and pregnancy. Semin Hematol 2003; 40:2125.

10 Russell MA, Carpenter MW, Akhtar MS, Lagattuta TF, Egorin MJ: Imatinib mesylate and metabolite concentrations in maternal blood, umbilical cord blood, placenta and breast milk. J Perinatol 2007;27:241-243. 